\title{
Correction to: Decolonizing and Feminizing Freedom
}

\section{Correction to:}

D. Noble, Decolonizing and Feminizing Freedom: A Caribbean

Genealogy, Thinking Gender in Transnational Times, https://doi.org/10.1057/978-1-137-44951-1

An error in the editing process unfortunately led to a re-edit of this book. The version supplied here has been corrected and approved by the author [Denise Noble]. 